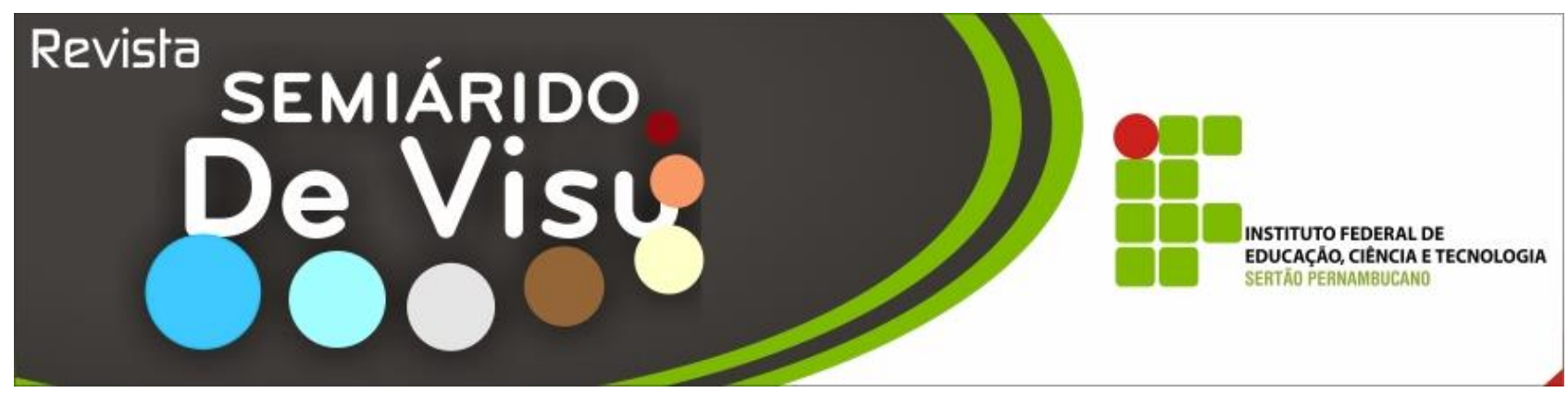

\title{
Percepção dos frequentadores de Área de Preservação Permanente em Petrolina-PE quanto ao meio ambiente e a degradação ambiental
}

\author{
Tayron Juliano Souza ${ }^{1}$, Miriam Cleide Cavalcante de Amorim ${ }^{1}$, José Antunes da Silva Neto ${ }^{1}$, \\ Eucymara França Nunes Santos ${ }^{1}$
}

${ }^{1}$ Universidade Federal do Vale do São Francisco - UNIVASF, campus Juazeiro-BA, Av. Antônio Carlos Magalhães, Bairro Santo Antônio, CEP: 48902-300, E-mail: tayron.js@ hotmail.com

\begin{abstract}
RESUMO: O presente trabalho visou obter a percepção de frequentadores da Área de Preservação Permanente (APP), às margens do rio São Francisco, na sede do município de Petrolina, PE sobre aspectos de meio ambiente e de degradação ambiental. Para coleta de dados foi proposto questionário estruturado que procurou identificar a percepção ambiental e degradação. Os resultados obtidos mostram que a população apresenta interesse por assuntos relacionados às questões ambientais, sendo os atores de maior interesse os que compreendem a faixa etária de 18 a 25 anos, enquanto que os entrevistados de 53 a 60 têm menor interesse. Dessa forma, verificam-se a importância do estudo da percepção ambiental e de degradação dos frequentadores da APP, como subsídios à gestão ambiental da APP urbana.
\end{abstract}

Palavras-chave: Orla fluvial, faixa etária, rio São Francisco.

\section{Perception of the regulars of Permanent Preservation Area in Petrolina-PE as the environment and environmental degradation}

\begin{abstract}
This study aimed to gain insight goers Permanent Preservation Areas (APP), the river São Francisco, in the town of Petrolina, PE on aspects of the environment and environmental degradation. For data collection was proposed structured questionnaire that sought to identify the perceptions and environmental degradation. The results show that the population has an interest in issues related to environmental issues, and the most interesting actors who comprise the age group of 18 to 25 years, whereas respondents from 53 to 60 have less interest. Thus, there is the importance of the study of environmental perception and degradation of APP goers, as subsidies to urban environmental management of APP.
\end{abstract}

Keywords: river edge, age group, São Francisco river. 
Tayron Juliano Souza et al.

\section{Introdução}

$\mathrm{S}$ egundo Palma (2005), entende-se por percepção a interação do indivíduo com o seu meio. Para Forgus (1981) percepção é um processo que recebe e extrai informações sobre o ambiente.

A percepção ambiental é um ramo da educação ambiental que envolve diferentes áreas de conhecimento, sendo um tema muito atual e de grande importância, pois sua análise pode determinar a necessidade da população, assim como dar embasamento na detecção de problemas, planejamento e solução dos mesmos (PALMA, 2005).

Segundo Minguet (1998), para entender a importância de avaliar a percepção ambiental através da perspectiva da educação construtiva, pode-se considerar que o conhecimento do meio não depende de suas características objetivas, mas da concepção que o sujeito tem delas e do sentido que lhes confere. O estudo da percepção ambiental é fundamental para que se possa compreender as inter-relações entre o homem e o ambiente, suas expectativas, satisfações e insatisfações, julgamentos e condutas (FERNANDES et al., 2011).

O Manual de Recuperação de Áreas Degradadas pela Mineração do IBAMA, citado por Tavares (2008) define que "a degradação de uma área ocorre quando a vegetação nativa e a fauna forem destruídas, removidas ou expulsas; a camada fértil do solo for perdida, removida ou enterrada; $e$ a qualidade $e$ o regime de vazão do sistema hídrico forem alterados. Ainda, segundo o autor, o conceito de degradação é relativo, embora esteja sempre associado à noção de alteração ambiental adversa, gerada na maioria das vezes, por atividades humanas.

Segundo Dias (1998), a degradação ambiental pode ser entendida como alterações das condições naturais que comprometem o uso dos recursos naturais (solos, água, flora, fauna, etc.) e reduzem a qualidade de vida das pessoas.

O surgimento de áreas degradadas no Brasil vem aumentado consideravelmente nos últimos anos, causando diversos problemas ambientais (BEZERRA et al., 2006). Segundo
Cruz et al. (2008), se os processos que ocorrem em determinada área tiverem alta magnitude $\mathrm{e}$ longa duração, podem gerar efeitos irreversíveis sobre o ambiente. As populações que residem nessas áreas estarão susceptíveis a consequências econômicas e sociais, como resultado do processo de degradação do solo e dos recursos hídricos.

Para Palma (2005), a pesquisa de percepção pode ser utilizada para avaliar a degradação ambiental de uma determinada região, e para entender os processos desta degradação. Portanto é necessário que o ser humano tenha consciência, racionalize os recursos naturais oferecidos pela natureza buscando o princípio da sustentabilidade para dar continuidade ao desenvolvimento econômico e do meio ambiente (QUEIROZ, 1997).

Área de Preservação Permanente (APP) é uma área em geral extensa, com certo grau de ocupação humana, dotada de atributos abióticos, bióticos, estéticos ou culturais, especialmente importantes para a qualidade de vida e bem-estar das populações humanas. De acordo com o novo Código Florestal brasileiro, instituído pela Lei 12.651 de 25 de maio de 2012, as APPs são áreas “...cobertas ou não por vegetação nativa, com a função ambiental de preservar os recursos hídricos, a paisagem, a estabilidade geológica, a biodiversidade, o fluxo gênico de fauna e flora, proteger o solo e assegurar o bem-estar das populações humanas".

A Resolução 303 de 20 de março de 2002 do Conselho Nacional de Meio Ambiente (CONAMA), dispõe sobre parâmetros, definições e limites de Áreas de Preservação Permanente (APP). O Artigo $3^{\circ}$ da referida Resolução, bem como o Art. $4^{\circ}$ do Código Florestal, define que em zonas rurais ou urbanas, a área situada em faixa marginal de qualquer curso d'água natural, desde a borda da calha do leito regular, com largura mínima de 500 (quinhentos) metros para os cursos d'água com mais de 600 (seiscentos) metros de largura, constitui uma APP, e, portanto as margens do rio São Francisco, com características predominantes da Caatinga, na 
Tayron Juliano Souza et al.

zona urbana da sede do município de PetrolinaPernambuco, enquadram-se nesta definição.

Ainda segundo o novo Código Florestal, para os casos de APP em áreas urbanas, assim entendidas as áreas compreendidas nos perímetros urbanos definidos por lei municipal, e nas regiões metropolitanas e aglomerações urbanas, os incisos $9^{\circ}$ e $10^{\circ}$ dispõe que "as faixas marginais de qualquer curso d'água natural que delimitem as áreas da faixa de passagem de inundação terão sua largura determinada pelos respectivos Planos Diretores e Leis de Uso do Solo, ouvidos os Conselhos Estaduais e Municipais de Meio Ambiente, sem prejuízo dos limites estabelecidos pelo inciso I do referido Art. 4".

$\mathrm{O}$ rio São Francisco tem uma extensão de $2700 \mathrm{~km}$, desde a sua nascente na Serra da Canastra (Minas Gerais) até a sua Foz no Oceano Atlântico. Sob o ponto de vista geográfico o Vale do São Francisco é tradicionalmente dividido em 4 regiões: Alto, Médio, Submédio e Baixo São Francisco e o Município de Petrolina com uma população urbana de 293.962 habitantes, localiza-se região geográfica do Submédio São Francisco.

$O$ fato da APP estar localizada numa área de zona urbana, diversas são as situações conflituosas geradas pelo fator turístico e de lazer devido à paisagem, por atividades comerciais e industriais, inserindo-se dois níveis de complexidade: o meio abiótico, referente ao ambiente físico-químico, e o meio biótico, referente às interações entre os organismos e o ambiente, e o meio socioeconômico e cultural (AMORIM, 2010).

Pela sua estratégica localização, as matas situadas nessas áreas têm vocação de servirem como corredores naturais de ligação entre fragmentos florestais e reservas; exercem papel fundamental na manutenção da qualidade da água, na conservação da biodiversidade e do patrimônio genético da flora e da fauna (PEREIRA et al., 2007). Uma das alternativas é o investimento no processo educativo (Educação Ambiental) que é "embasado na busca de um equilíbrio entre o homem e o ambiente, com vista à construção de um futuro pensado e vivido numa lógica de desenvolvimento e progresso" (ADAMS, 2010).

Então, torna-se necessário saber em qual ambiente estamos inseridos para que possamos proteger e cuidá-lo da melhor forma possível. Assim, a partir do instrumento de pesquisa, a percepção ambiental pode contribuir para elaboração de projetos e atividades ambientais, diante da concepção dos atores da pesquisa.

Dessa forma, este trabalho objetivou obter a percepção sobre aspectos de meio ambiente e de degradação ambiental, dos frequentadores da área de proteção permanente (APP), às margens do rio São Francisco, em área urbana da sede do município de Petrolina, $\mathrm{PE}$, visando gerar subsídios à gestão ambiental da APP urbana.

\section{Material e métodos}

\section{estudo \\ Caracterização ecológica da área de}

O Município de Petrolina possui uma população urbana de 293.962 habitantes (IBGE, 2012), localizando-se na região geográfica do Submédio São Francisco. A vegetação é do tipo Caatinga hiperxerófila. Possui precipitação pluviométrica média anual de 1.059,6 milímetros. A região da zona urbana de Petrolina, às margens do rio São Francisco, vai desde a Foz do Riacho Vitória até as proximidades da Pedra do Bode, com uma extensão de 10,3 km, constituindo-se em Área de Proteção Ambiental conforme Artigo $4^{\circ}$ do Código Florestal Brasileiro e o Artigo $3^{\circ}$ da Resolução 303 de 20 de março de 2002 do CONAMA.

A região avaliada neste estudo está compreendida no trecho da Orla Fluvial I, com extensão de 6 km, conforme Figura 1. 
Tayron Juliano Souza et al.

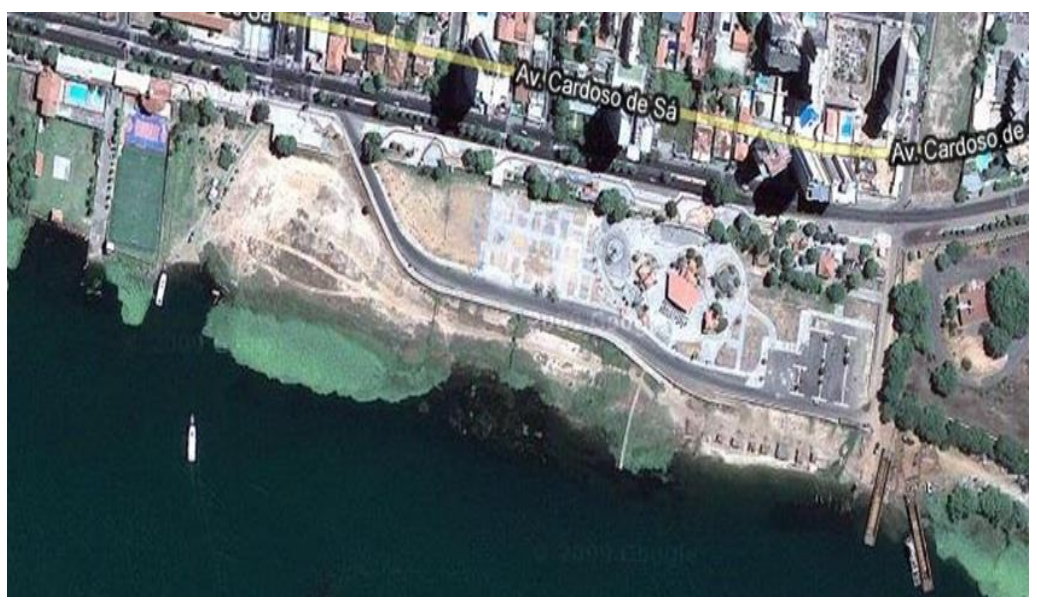

Figura 1: Trecho da Orla de Petrolina em estudo.

\section{Instrumento de coleta de dados}

O instrumento utilizado para a coleta de dados para avaliação da percepção sobre meio ambiente e degradação ambiental dos frequentadores da APP, trecho da Orla Fluvial I, foi um questionário caracterizado como estruturado. Para tanto foram aplicados 142 questionários, durante o período de março a maio de 2010.

Para se obter a percepção dos entrevistados quanto às questões de meio ambiente, foram aplicadas as seguintes perguntas:

$\checkmark$ Você tem interesse por assuntos relacionados ao meio ambiente?

$\checkmark$ Você conhece problemas ambientais na Orla de Petrolina?

$\checkmark$ Você sabe onde é descartado o esgoto de Petrolina?

Quanto à percepção dos entrevistados acerca do entendimento sobre áreas degradadas, questionou-se:

$\checkmark$ O que é área degradada?

$\checkmark$ Você acha que as margens do rio São Francisco estão degradadas?

No que diz respeito à disponibilidade para pagamento de taxa de recuperação das áreas degradadas, foi realizado o seguinte questionamento:

$\checkmark$ Você seria a favor de uma taxa para recuperação de áreas degradadas às margens do rio São Francisco?

\section{Procedimento de coleta de dados}

O método para levantamento dos dados foi de forma estratégica, quanto à delimitação do campo de pesquisa, definindo-se como forma de abordagem a entrevista com aplicação de questionário em função da disponibilidade dos entrevistados em responder ao mesmo, de forma aleatória a fim de mesclar a amostra da população. A coleta de dados foi realizada em diferentes turnos (manhã, tarde e noite), em locais com grande fluxo de pessoas, tais como: porto da barquinha, bares e restaurantes localizados na orla, calçada de caminhada, ponto de moto táxis e de ônibus.

\section{Procedimento estatístico}

Os dados foram tabulados com o auxílio de uma planilha EXCEL, a partir dos quais foram confeccionados gráficos de barras através das distribuições das frequências relativas das idades. $\mathrm{O}$ teste não paramétrico qui-quadrado foi realizado para comparar divergências entre as frequências observadas e esperadas dos grupos de faixa etária, que têm percepção ambiental na área de proteção permanente às margens do rio São Francisco. 
Tayron Juliano Souza et al.

Resultados e discussão

\section{Perfil dos entrevistados da área de estudo}

Como mostrado na Figura 2, à maioria dos entrevistados na Orla Fluvial I, pertenciam às faixas etárias que compreende os atores de
18 a 25 anos e 25 a 32 anos $(38 \%$ e $20 \%$ respectivamente). A menor faixa é representada por atores com idade entre 53 a 60 anos (1\%).

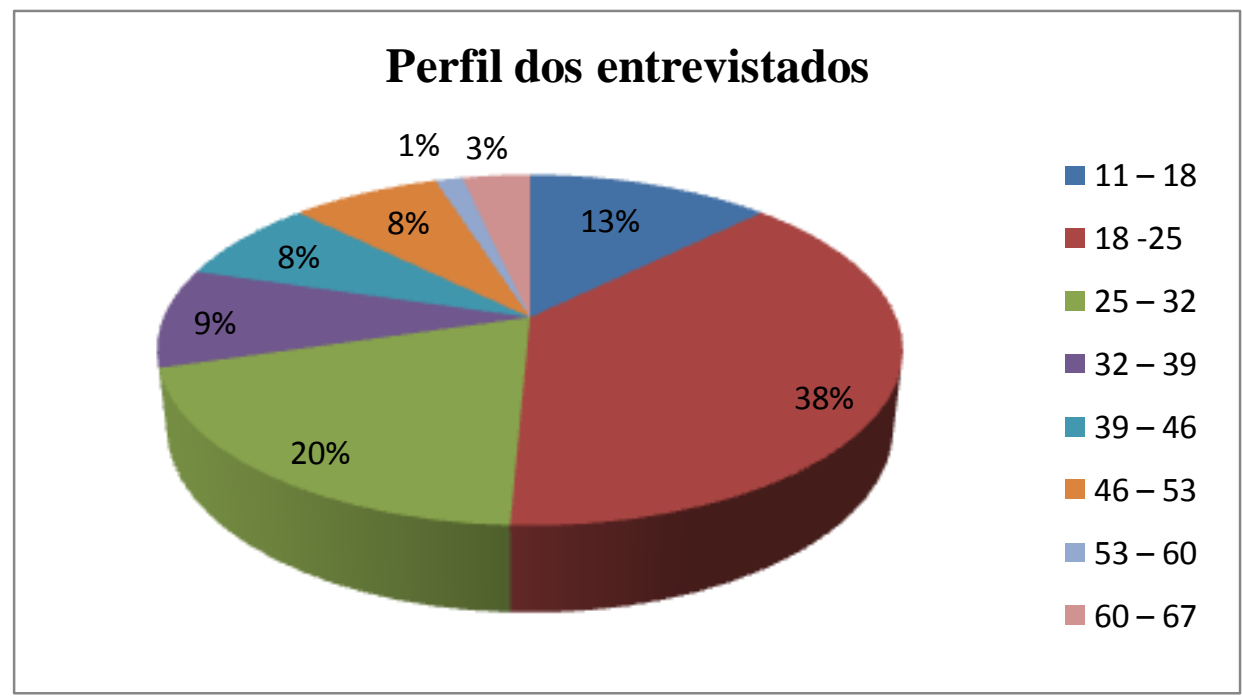

Figura 2: Perfil dos entrevistados na Orla Fluvial I quanto à faixa etária.

\section{Resultados relacionados às questões de meio ambiente}

Quando questionados sobre o interesse por assuntos relacionados ao meio ambiente observou-se que a maior parte da amostra respondeu sim, ou seja, 94\% dos entrevistados apresentam interesse, conforme Figura 3a. Quanto à faixa etária, nota-se que os atores com idade entre 18 a 25 anos apresentaram maior interesse por assuntos ambientais, enquanto que a faixa etária de 53 a 60 apresentou menor interesse (Figura 3b). O resultado do teste quiquadrado mostra que as respostas são independentes quanto à faixa etária dos informantes. Resultados semelhantes foram encontrados por Fernandes et al. (2011) que encontraram valores superiores a $90 \%$ quanto ao interesse a assuntos relacionados ao meio ambiente.

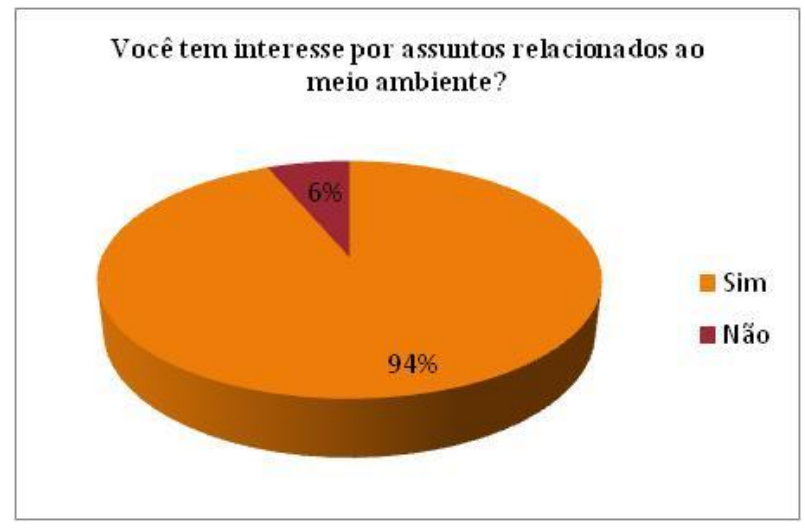

(a)

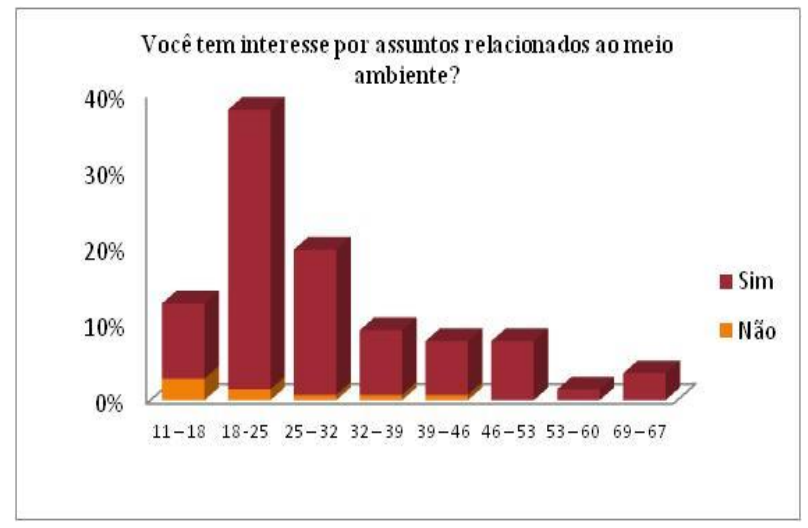

(b)

Figura 3: Interesse por assuntos relacionados ao meio ambiente. a) Independente da faixa etária. b) Diferentes faixas etárias. 
Tayron Juliano Souza et al.

Quando perguntados se conhecem problemas ambientais na Orla de Petrolina, $82 \%$ da amostra afirma conhecer tais problemas (Figura 4a), dentre eles, poluição do rio através do lançamento de esgoto no mesmo sem prévio tratamento. Os demais $18 \%$ não souberam responder, possivelmente pela falta de informação sobre problemas ambientais.

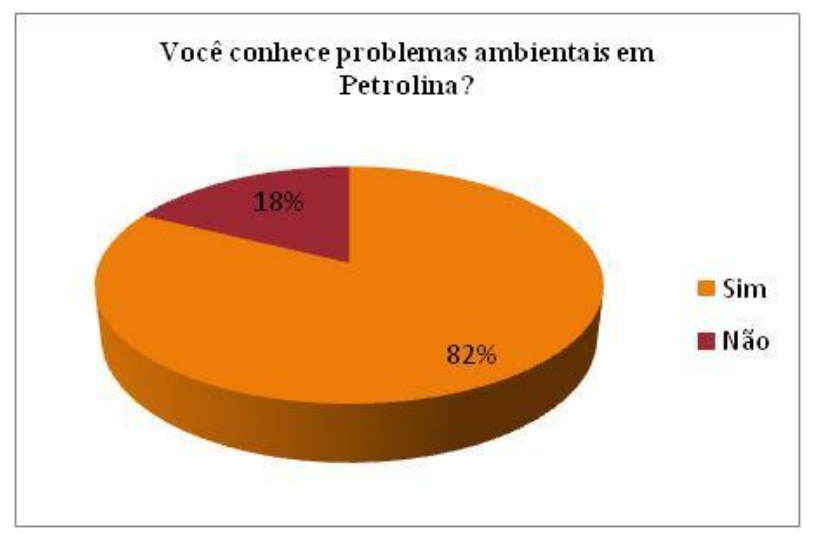

(a)
Quando agrupados em diferentes faixas etárias pode ser observado que os atores no intervalo de 18 a 25 anos apresentaram maiores percentuais sobre conhecimento de tais problemas (Figura 4b), sendo capazes de indentificá-los. $\mathrm{O}$ menor percentual compreendeu a faixa entre 53 a 60 anos.

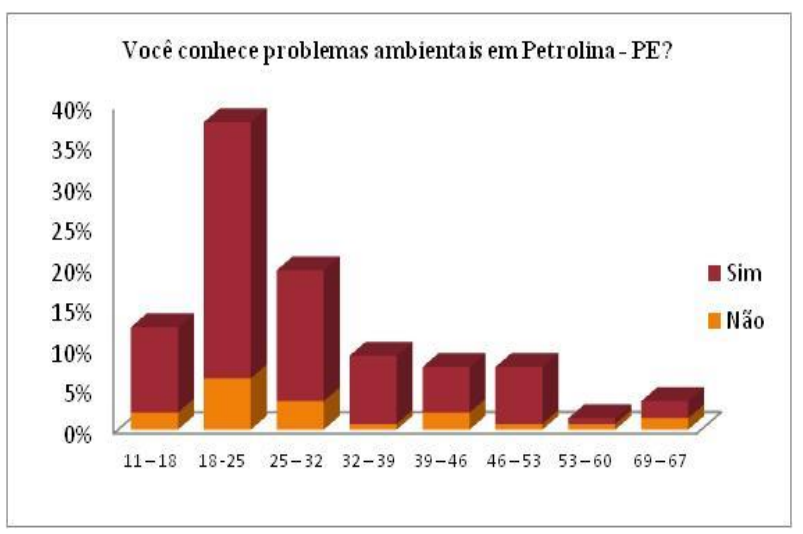

(b)

Figura 4: Problemas ambientais em Petrolina: a) Independente da faixa etária. b) Diferentes faixas etárias.

Quando questionados se sabem onde é descartado o esgoto da cidade de Petrolina, $64 \%$ da amostragem respondeu que sim, acrescentando que seria o rio São Francisco, enquanto que $36 \%$ afirmaram não saber para onde vão os esgotos após serem liberados de sua residência ou casa comercial (Figura 5a). Isto indica que uma parcela da população pode não estar informada a cerca do lançamento de esgotos de sua cidade. De acordo com Amorim (2010) foi identificado o lançamento de esgotos não tratados nas margens do rio São Francisco, especificamente na região em estudo, ferindo a Resolução CONAMA 357/05 que não permite o lançamento de efluentes, direta ou indiretamente, nos corpos hídricos, sem o devido tratamento. Nos diferentes intervalos, independentes da idade os atores souberam responder sobre o destino dos efluentes, sendo a faixa etária de 18 a 25 anos a que apresentou maiores percentuais sobre o conhecimento do local de descarte do esgoto, enquanto que os menores percentuais ocorreram entre os atores de 53 a 60 anos (Figura 5b).

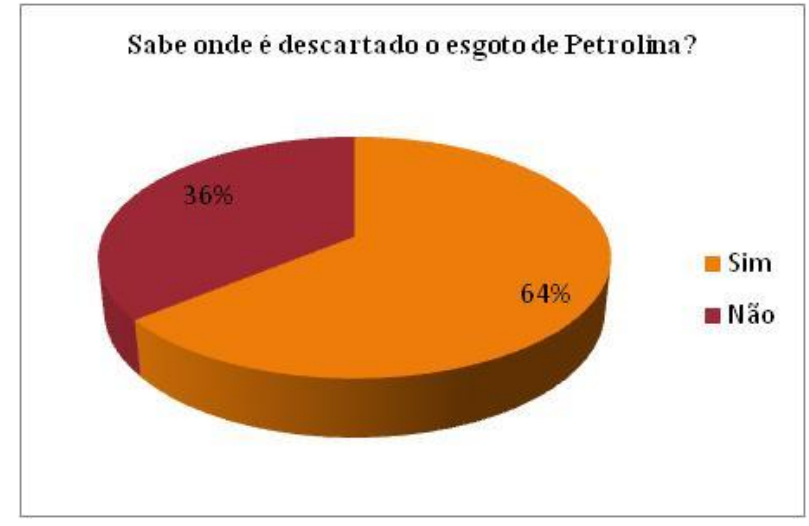

(a)

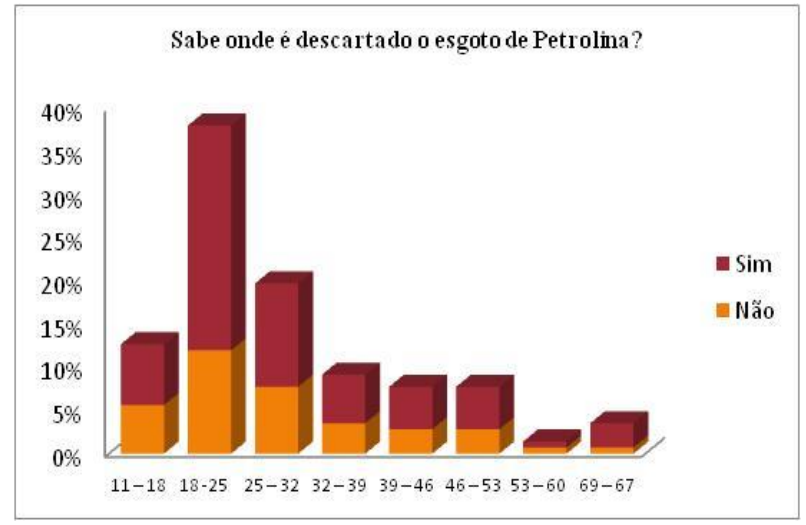

(b)

Figura 5: Descarte de esgoto no município de Petrolina-PE. a) Independente da faixa etária. b) Diferentes faixas etárias. 
Tayron Juliano Souza et al.

\section{Resultados relacionados ao entendimento sobre áreas degradadas}

A Figura 6a mostra que independente da idade, quando abordados sobre o que é área degradada, apenas $28 \%$ da população não soube responder. Quando agrupados por idade foi observado que jovens entre 18 e 25 anos (30\%) apresentaram maiores percentuais sobre

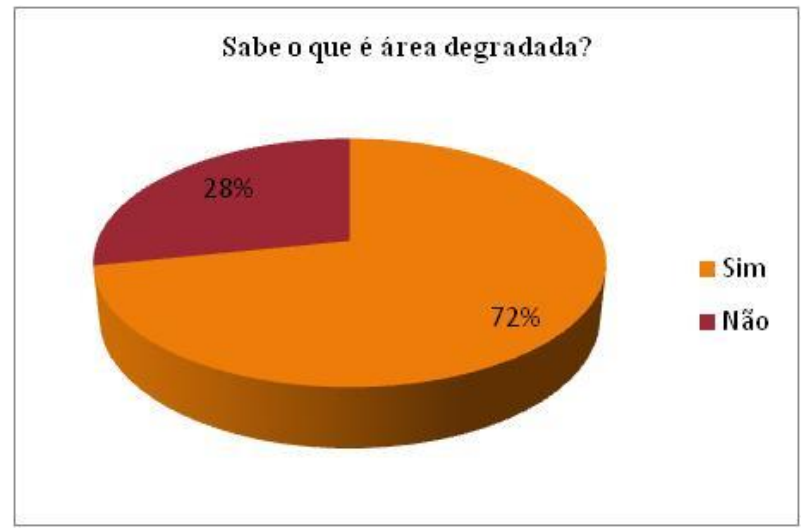

(a) o entendimento de áreas degradadas, o que indica melhor compreensão no conteúdo abordado, enquanto que os entrevistados de 53 a 60 anos (1\%) apresentaram menores percentuais (Figura 6b). O resultado do teste qui-quadrado para esta pergunta apresentou-se significativo à 5\%, isto é, houve influência das diferentes faixas etárias ao se perguntar o que é área degradada.

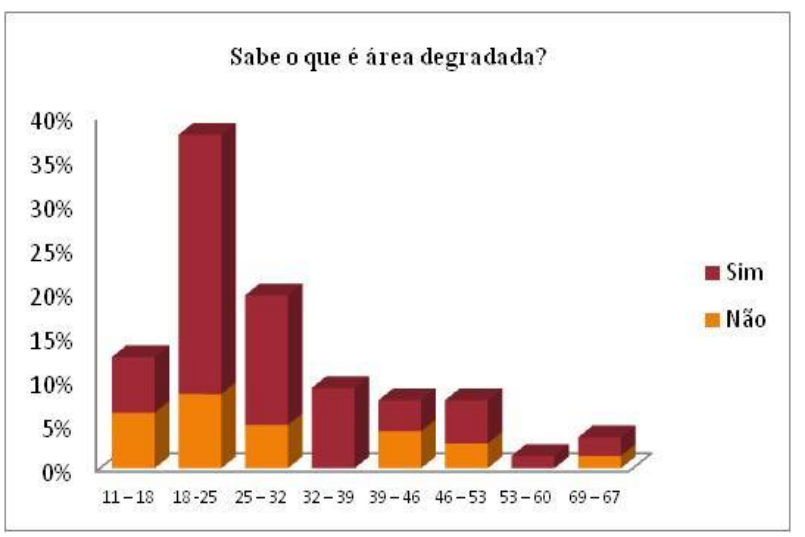

(b)

Figura 6: Conhecimento sobre área degradada a) Independente da faixa etária. b) Diferentes faixas etárias.

Quando abordados sobre a degradação das margens do rio São Francisco, foi observado que $88 \%$ dos entrevistados acham que as mesmas estão degradadas, (Figura 7a), fato este que corrobora a pergunta anterior, a qual mostra que $72 \%$ dos atores sabem o que é área degradada. Quando separados por faixa etária é observado que entrevistados com idade entre 18 a 25 anos (32\%), apresentaram os maiores percentuais na identificação de degradação às margens do rio São Francisco (Figura 7b). O menor percentual foi na faixa de 53 a 60 anos $(1 \%)$.

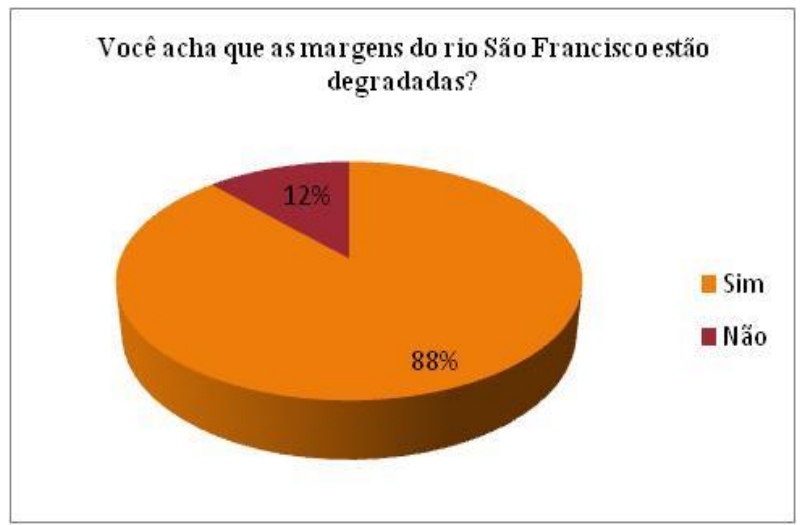

(a)

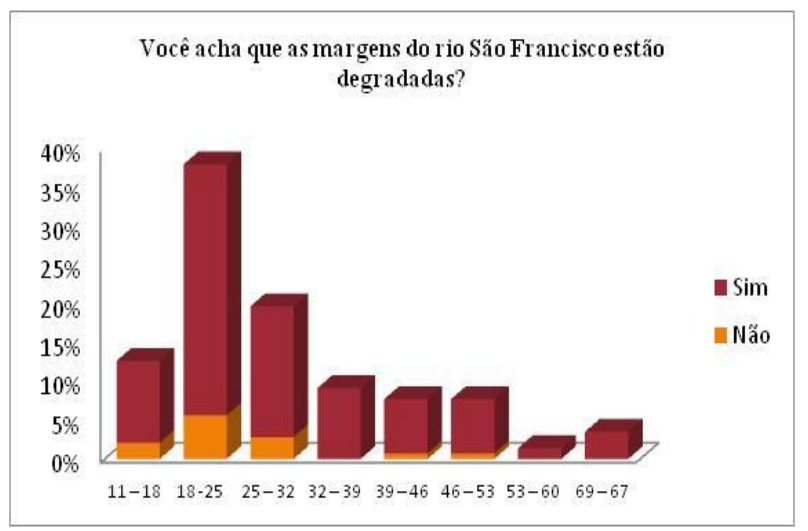

(b)

Figura 7: Conhecimento quanto a degradação as margens do rio São Francisco. a) Independente da faixa etária. b) Diferentes faixas etárias. 
Tayron Juliano Souza et al.

\section{Resultados relacionados à disponibilidade para pagamento de taxa para recuperação de áreas degradadas}

Diante dos problemas enfrentados pelo processo de degradação, os entrevistados foram abordados quanto a disponibilidade para pagamento de taxa para recuperar as margens do rio e foi observado que $68 \%$ dos atores estariam dispostos ao pagamento, enquanto que $32 \%$ seriam contra (Figura 8a). Os que foram contra justificaram sua posição afirmando acreditar que o governo é responsável por tal função ou mesmo que essa arrecadação não chegaria aos devidos fins. Para diferentes faixas etárias foi observado que os entrevistados entre 18 a 25 anos apresentam maiores percentuais (26\%) a favor do pagamento de tais taxas, enquanto que o menor percentual a favor esteve no grupo de 53 a 60 anos (1\%), conforme Figura 8b. O resultado do teste qui-quadrado para esta pergunta apresentou significância a $5 \%$, mostrando-se que houve influência das diferentes faixas etárias ao se perguntar sobre a disponibilidade ao pagamento de taxa para recuperação das áreas degradadas.

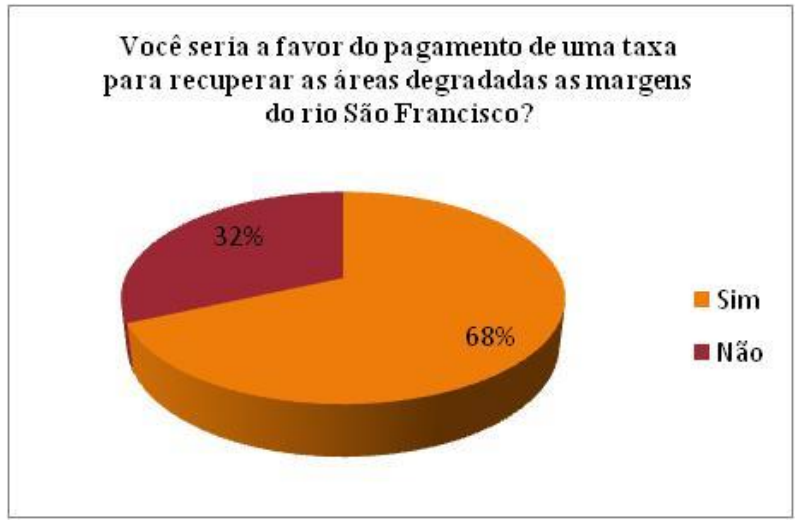

(a)

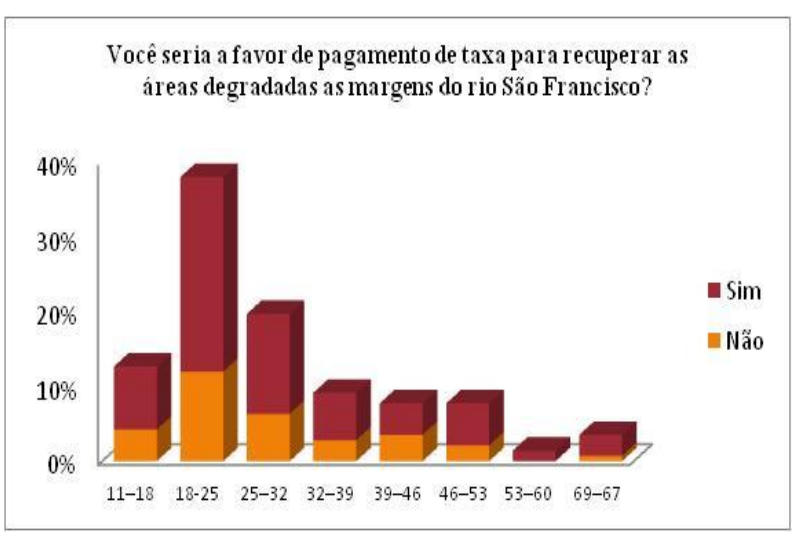

(b)

Figura 8: Disponibilidade par pagamento de taxa para recuper as áreas degradadas. a) Independente da faixa etária. b) Diferentes faixas etárias..

\section{Conclusões}

A pesquisa sobre a percepção dos atores da Orla Fluvial I em Petrolina, PE, quanto a aspectos de meio ambiente e de degradação ambiental da área, mostra que a maior parte dos frequentadores tem interesse por assuntos ambientais, conhecem os problemas ambientais da respectiva área e sabem o que é uma área degradada. Consequentemente, grande parte dos entrevistados sabe que o esgoto da cidade de Petrolina é descartado no rio São Francisco, e também acham que as margens do rio estão degradadas. Quanto à disponibilidade para pagamento de taxa de recuperação das áreas degradadas às margens do rio São Francisco, mais da metade dos entrevistados afirmaram estar dispostos a contribuir.

Portanto, conclui-se que o estudo permitiu obter a percepção de frequentadores da área de proteção permanente (APP), às margens do rio São Francisco, na sede do município de Petrolina, PE, quanto a aspectos ambientais e de degradação ambiental. Os referidos dados podem subsidiar programas de gestão e educação ambiental visando à minimização de problemas ambientais, bem como, a conservação da APP às margens urbanas do rio São Francisco, a partir da identificação preliminar do conhecimento dos envolvidos acerca da temática abordada.

\section{Referências}

ADAMS, B.G. Educação Ambiental. Disponível em: $<$ http://www.apoema.com.br/definicoes.htm>. Acesso em 16 mar. 2010.

AMORIM, M.C.C. Impactos ambientais em áreas de proteção ambiental urbana margem do Rio São Francisco, Petrolina, PE. I Congresso 
Tayron Juliano Souza et al.

Baiano de Engenharia Sanitária e Ambiental. Salvador. 2010.

BEZERRA， F.B.; OLIVEIRA， M.A.C.L.; PEREZ, D.V.; ANDRADE, A.G.; MENEGUILLI, N.D.A.; Lodo de esgoto em revegetação de área degradada. Pesq. agropec. bras. Brasília, v.41, n.3, p.469-476, mar. 2006.

BRASIL. Resolução CONAMA No 303, 20 de março de 2002. Conselho Nacional do Meio Ambiente. CONAMA, Brasília, DF, março de 2002.

BRASIL. Lei $\mathrm{n}^{\circ} 12.651$, de 25 de maio de 2012. Institui o Código Florestal. Brasília, 15 de setembro de 2012.

CRUZ, C.E.B.; LIMA, J.S. BRITO A.V.D.C.B.; Fatores de degradação ambiental nos Agropolos do Ceará. In: XLVI Congresso da sociedade brasileira de economia, administração e sociologia rural, 2008.

DIAS, R. L. F. Intervenções públicas e degradação ambiental no semiárido cearense $(O$ caso de Irauçuba). Dissertação de Mestrado em Desenvolvimento e Meio Ambiente, PRODEMA. Universidade Federal do Ceará. Fortaleza. 139 fls, 1998.

FERNANDES, R.S.; SOUZA, V.J.D.; PELISSARI, V.B.; FERNANDES, S.T. Uso da percepção ambiental como instrumento de gestão em aplicações ligadas às áreas educacional, social e ambiental. Disponível em: $<$ http://www.anppas.org.br/encontro_anual/enc ontro2/GT/GT10/roosevelt_fernandes.pdf>.

Acesso em 15 Nov. 2011.

FORGUS, R.H. Percepção: o processo básico do desenvolvimento cognitivo. ed. E.p.u, 1981.

IBGE, Censo Demográfico de 2010. Fundação Instituto Brasileiro de Geografia e Estatística, dados referentes ao município de Petrolina-PE. Disponível

em:<http://www.ibge.gov.br/cidadesat/painel/p ainel.php?codmun=261110 . Acesso em set. 2012.
MINGUET, P.A. A construção do conhecimento na educação. Porto Alegre: ArtMed. p.181. 1998. In: KITZMANN, D.; ASMUS,M.L.; Avaliação da percepção ambiental. Um estudo de caso com trabalhadores avulsos do Porto do Rio Grande. Rev. Eletrônica do Mestr. Educ.Ambiental, 1517-1256, p. 56-73, 1998

PALMA, I.R. Análise da percepção ambiental como instrumento ao planejamento da educação ambiental. Dissertação para a obtenção do título de Mestre em Engenharia. Universidade Federal do Rio Grande do Sul, Porto Alegre, 78 fls. 2005.

PEREIRA, F.S. GOMES, J.E. PERES, U.B.; Avaliação da recuperação de área degradada "Estação de tratamento de esgoto Tibiriçá, no município de Garça - SP”. Rev. Científica Elet. de Eng. Florestal. Ano V, n. 09, São Paulo, 2007.

QUEIROZ, Alvamar Costa. A Inserção da Dimensão Ambiental na Reorientação

Curricular. Dissertação (Mestrado). Programa de Pós-Graduação em Educação,

Universidade Federal do Rio Grande do Norte. Natal, 1997.

TAVARES, S. R. D. L. Curso de recuperação de áreas degradadas: a visão da Ciência do Solo no contexto do diagnóstico, manejo, indicadores de monitoramento e estratégias de recuperação. Rio de Janeiro: Embrapa Solos, p.228, 2008. 